\title{
Erratum to: Subsidiary Initiatives in the Institutional Environment
}

\author{
Jens Hamprecht · Julia Schwarzkopf
}

Received: 1 April 2012/Revised: 5 May 2013/Accepted: 7 November 2013/

Published online: 8 July 2014

(C) Springer-Verlag Berlin Heidelberg 2014

\section{Erratum to: Manag Int Rev DOI 10.1007/s11575-013-0191-2}

In the original article, there has been a mistake in the author names. The authors of this article are Jens Hamprecht and Julia Schwarzkopf, not Julia Hamprecht and Jan Schwarzkopf.

We regret this mistake and any inconvenience caused by it.

\begin{abstract}
We study subsidiaries of a MNC and research why they implement initiatives that deviate from organizational values of headquarters. Initially we relied only on the concept of institutional duality and expected that pressures in the institutional environment and values of headquarters explain the agency of the subsidiaries. But the results of our extensive participatory observation showed that the organizational values of subsidiaries (rather than those of headquarters) helped explain the subsidiaries' actions. In conclusion, we find that there are limits to the predictive power of the concept of institutional duality. Our study shows that a distinction between values of headquarters and values of subsidiaries is necessary in order to understand the agency of subsidiaries. We suggest a concept of 'institutional trinity' that distinguishes between these two values as well as pressures in the institutional environment. Our research demonstrates that an MNC can benefit from a subsidiary that develops its own organizational values. If
\end{abstract}

The online version of the original article can be found under doi:10.1007/s11575-013-0191-2.

J. Hamprecht · J. Schwarzkopf $(\bowtie)$

Group for Sustainability and Technology, Department of Management, Technology, and

Economics, Swiss Federal Institute of Technology, Zurich, Switzerland

e-mail: julia.schwarzkopf@gmail.com 
headquarters is subsequently ready to adopt some of these subsidiary values, it may be able to adapt more easily to a changing institutional environment.

Keywords Climate change - Institutional duality • Institutional theory • Subsidiaries 